\title{
Dissidências de um curso: transicionando gêneros e currículos na formação em psicologia
}

\author{
Dissidences of a course: transitioning genders and curricula in psychologist \\ education
}

Maria Carolina Fonseca Barbosa Roseiro; Alexsandro Rodrigues; Maria Elizabeth Barros de Barros

Universidade Federal do Espírito Santo

\section{RESUMO:}

Considerou-se, neste artigo, as normalizações das sexualidades e dos gêneros dissidentes, e os jogos de verdade que as acompanham, na constituição de discursos que legitimam a Psicologia como campo disciplinar alinhado aos discursos patologizantes das subjetividades. Ao questionar-se o privilégio desses discursos em relação à produção de conhecimento que emerge dos ativismos e vivências dissidentes, abordou-se, no campo dos currículos em Psicologia, os processos de subjetivação na produção desses saberes. Afirmou-se, contudo, a produção de discurso acadêmico como campo estratégico, no qual somos convocadas(os) a posicionamentos e implicações que se articulam a esses e outros ativismos e movimentos sociais. Na transversalidade desses percursos, e por análise de implicações, entre essas dissidências, acompanhou-se os deslocamentos do lugar de um não-homem, pela descolonização do sujeito epistêmico e de sua universalidade, transicionando-se dos binarismos de gênero ao coletivo das enunciações.

Palavras-chave: gênero na educação; subjetividade; psicologia; currículos; transversalidade; sexualidade; agenciamentos coletivos de enunciação; saber e poder

\begin{abstract}
:
In this article, it was considered the normalization of sexualities and dissident genres, and the truth games that accompany them, in the constitution of discourses that legitimize Psychology as a disciplinary field aligned with the pathologizing discourses of subjectivities. When questioning the privilege of these speeches in relation to the production of knowledge that emerges from dissident activisms and experiences, the subjectivity processes in the production of this knowledge were addressed in the field of curricula in Psychology. However, the production of academic discourse as a strategic field was affirmed, in which we are summoned to positions and implications that are articulated to these and other activisms and social movements. In the transversality of these paths, and through analysis of implications, among these dissidences, the displacement of the place of a non-man was accompanied, by the decolonization of the epistemic subject and its universality, moving from gender binarisms to the collective of enunciations. [collective disposals of enunciation]
\end{abstract}

Key-words: gender in education; subjectivity; psychology; curricula; transversality; sexuality; collective enunciation assemblages; knowledge and power 


\section{Dos sujeitos e objetos - desapropriando posições e regimes de verdade}

O presente artigo refere-se à dissertação de mestrado apresentada ao Programa de Pós-Graduação em Psicologia Institucional da Universidade Federal do Espírito Santo (PPGPSI/Ufes), concluída e aprovada em 2017, voltada às práticas curriculares e produção de discursos em Psicologia. A pesquisa que o precede visou considerar as dissidências sexuais e de gêneros como dispositivos estratégicos neste campo de saberpoder, quanto aos quais buscou-se chegar a modos outros de se constituírem regimes de verdade e sujeitos epistêmicos. O percurso dessa pesquisa-intervenção, que se propôs à análise de implicações nos processos formativos de um estágio em docência, orientou-se a acompanhar, por uma atenção cartográfica, os currículos praticados e pensados nos cotidianos quanto às multiplicidades das expressões de gênero e nas dispersões desses contornos, colocando em análise os referenciais de um pensamento hetero (WITTIG, 1978), com o qual se coaduna o sujeito epistêmico universal - do qual são signatários saberes psi normalizadores da diferença, na produção de desigualdades.

Situam-se a referida pesquisa e este texto entre os estudos dos processos de subjetivação, considerando-se como fundamentais as afirmações de Foucault (2004; 2012: 87) quanto a uma produção política dos discursos e dos sujeitos do conhecimento, bem como dos seus processos de objetivação. Partimos da perspectiva de relações de poder que se articulam, no dispositivo da sexualidade, enquanto objeto legitimado ao campo da Psicologia, por meio de procedimentos que normatizam, isto é, criam regras, quanto ao que pode ser válido ou não nos discursos. Constituindo discursos e sendo constituída por práticas discursivas, essa produção de verdades faz-se em coengendramento com "processos de subjetivação e de objetivação que fazem com que o sujeito possa se tornar, na qualidade de sujeito, objeto de conhecimento" (FOUCAULT, 2004: 235-236). Tal afirmação refere-se aos jogos de verdade nos quais a subjetividade advém "como a maneira pela qual o sujeito faz a experiência de si mesmo", reconhecendo-se como campo de saber. Portanto, a subjetividade que interessa ao discurso científico e às suas disciplinas será nomeada de uma certa forma, a depender da experiência de si que se pretende regular. Ou seja, não será qualquer sujeito que se colocará como objeto, assim como não será qualquer experiência subjetiva que será objetificada.

Ao tratar da produção de saberes e dos mecanismos de poder nos processos de subjetivação, este artigo não se refere a uma pesquisa proposta como análise isenta e 
neutra, sobre engrenagens já dadas, quanto às quais apenas procederíamos ao reconhecimento de formas em contornos absolutos, ou de representações decodificáveis em significados ocultos. Produções, mecanismos e processos são palavras que nos conduzem a um movimento de pesquisa em que os tensionamentos nos interessam - onde as práticas discursivas se atritam e se articulam nos jogos de verdade que autorizam e desapropriam saberes na Psicologia, em sua legitimação para o exercício de normalização das sexualidades.

Constituindo-se a escrita do texto por uma atenção cartográfica (KASTRUP, 2009), que assumimos como metodologia de pesquisa, no sentido de acompanhar processos (BARROS; KASTRUP, 2009), também tomamos a noção de analisadores em Lourau (2004: 70), como contraponto aos "discursos explicativos" dos conjuntos teóricos e à “dominação analítica" pela via da interpretação. A análise, desse modo, não se conduz às totalidades, mas à sua decomposição, e não se dispõe a explicar esses elementos, mas a evidenciá-los na composição de um conjunto - como processo, antes de ser forma. Não nos interessa, portanto, o caráter de desvelamento, de revelação de um não-dito que essas noções nos propõem, mas os processos catalisadores do sentido, que fazem romper unidades pré-determinadas no percurso da investigação. Os analisadores são aqui compreendidos como dispositivos cartográficos, já que não partem de mapas prontos, nem se dispõem a desenhá-los como espaços já dados. Os analisadores são “manifestações de não conformidade com o instituído" (LOURAU, 2004: 69), mas dessa não conformidade, por sua atividade instituinte, apresenta-se aí o instituído em sua desnaturalização.

Este caminho metodológico apostou nos referenciais da análise institucional como possibilidade de operar na grupalidade, de mobilizar-nos entre coletivos, numa pesquisaintervenção que se perpassa por encontros com pessoas, mas que não necessariamente ritualiza-se por ferramentas consagradas como instrumentos de cisão entre campo/objetos de pesquisa, de onde se coletam dados, e de outro lado "o pesquisador", único agente da análise ou da intervenção. Buscamos, por outro lado, considerar as análises que se fizeram nos cotidianos da prática docente, afirmando-se que: "Estar implicado (realizar ou aceitar a análise de minhas próprias implicações) é, ao fim e ao cabo, admitir que sou objetivado por aquilo que pretendo objetivar: fenômenos, acontecimentos, grupos, ideias, etc." (LOURAU, 2004: 147- 148).

Interessou-nos, nesta pesquisa, atravessar por deslocamentos ou porosidades na 
produção de currículos em psicologia, que de agora em diante será registrada em letra minúscula, pois não nos interessa reafirmar o seu privilégio substantivo como "domínio de saber", mas os seus tensionamentos e confluências com expressões das dissidências sexuais e de gênero. A cartografia, dessa forma, colocou-se como estratégia metodológica na constituição de um campo das práticas curriculares, passando por processos que nos levaram à proposição e oferta de uma disciplina no estágio em docência, como território e percurso para a pesquisa.

\section{Das sexualidades e gêneros: transicionando normalizações}

Transicionar aqui faz alusão ao sentido atribuído aos processos da produção e da (des)construção dos corpos de pessoas trans - isto é, pessoas que não se identificam com o gênero ou expressões de gênero atribuídos quando nasceram (JESUS, 2012: 10). A abreviação trans se refere a pessoas transgêneras, o que abrange designações muito diversas, como travestis, transexuais e outros. A partir dessa designação, as pessoas trans cunharam o termo cisgênero para designar as pessoas que não são trans. $O$ termo cis significa "do mesmo lado", referindo-se a pessoas que se mantêm na mesma designação de gênero desde que nasceram. A denominação cis tem o propósito de reverter o sentido da categorização, que parte da sua normalidade, supostamente neutra, para a designação dos desviantes, que seriam trans.

Nesse mesmo sentido consideramos questionamentos que concernem à psicologia ter se legitimado enquanto regime de verdade na constituição deste campo de saber, que é o da sexualidade, ao fazer funcionar o binômio normal-patológico - pela naturalização de uma estrutura psíquica, ou de uma condição humana, ou ainda de um comportamento social, a depender das referências a que se adere; de toda sorte, concepções de um sujeito que é objeto de conhecimento e que se conforma a partir de parâmetros que não problematizam a heterossexualidade, dessa forma compreendida e afirmada como se fosse compulsória.

Os discursos que acima de tudo nos oprimem, lésbicas, mulheres, e homens homossexuais, são aqueles que tomam como certo que a base da sociedade, de qualquer sociedade, é a heterossexualidade. Estes discursos falam sobre nós e alegam dizer a verdade num campo apolítico, como se qualquer coisa que significa algo pudesse escapar ao político neste momento da história, e como se, no tocante a nós, pudessem existir signos politicamente insignificantes. Estes discursos da heterossexualidade oprimem-nos no sentido em que nos impedem de falar a menos que falemos nos termos deles (WITTIG, 1978). 
A desconstrução de uma heterossexualidade compulsória, por meio da problematização dos binarismos de gênero, colocou-se como uma inflexão em meio às referências mais convencionais dos saberes psi. Essa inflexão parte da leitura crítica de um sistema epistemológico/ontológico normalizante das sexualidades e, recorrentemente, depreciativo da posição feminina. Considerando que a identidade da mulher, como "sujeito político do feminismo", seja uma categoria a problematizar, Butler (2015) afirma que a relação binária entre os gêneros conforma-se a uma matriz heterossexual que sustenta a hierarquia dos gêneros, e propõe que o feminismo se coloque como subversão da identidade, convocando-nos a uma questão fundamental: “O que acontece ao sujeito e à estabilidade das categorias de gênero quando o regime epistemológico da presunção da heterossexualidade é desmascarado, explicitando-se como produtor e reificador dessas categorias ostensivamente ontológicas?” (BUTLER, 2015: 8).

Ao afirmar-se que a autoridade dos discursos em psicologia foi constituída e segue legitimando-se por práticas normalizadoras que incidem nas sexualidades e nas diferenças de gênero, discute-se que outros regimes de verdade podem ser construídos ao refutarmos o privilégio desses discursos acadêmicos em relação a outros modos de produção de conhecimento, que emergem dos ativismos e das vivências das dissidências de gênero. Ainda nos propomos, todavia, à produção de discurso acadêmico, que afirmamos como campo estratégico, no qual somos convocadas a posicionamentos e implicações éticoestético-políticas, que se articulam a esses e outros ativismos e movimentos sociais. Utilizamos preferencialmente a noção de dissidências sexuais e de gênero, que tem sido adotada por estudos e ativismos queer, referindo-se a grupos e ações não normatizados, autogestionados ou independentes, que são críticos aos objetivos assimilatórios do movimento LGBT, os quais reforçariam o contexto sociocultural das normatizações heterossexistas.

As dissidências dizem respeito às expressões de gênero e sexualidade que são identificadas como abjetas, marginais, em relação ao modelo de uma heterossexualidade que se constitui enquanto um regime político compulsório e normalizador das expressões de gênero e sexualidades. Queer é termo pejorativo utilizado na língua inglesa como insulto contra pessoas homossexuais. A palavra foi ressignificada por movimentos homossexuais e travestis nos EUA, a partir da década de 1970, como autodenominação, referindo-se a atitudes e pessoas contestatórias à heteronormatividade. Os estudos queer emergiram “em fins da década de 1980, em oposição aos estudos sociológicos sobre 
minorias sexuais e gênero" que "tratavam a ordem social como sinônimo de heterossexualidade [...] e terminavam por manter e naturalizar a norma heterossexual" (MISKOLCI, 2009: 150-151).

Nesse sentido, podemos ressaltar que os estudos de gênero vinculados a essas estratégias de subversão das identidades não emergiram da "genialidade" de doutores e doutoras, mas dos trânsitos que essas e esses pesquisadores tiveram nas vivências das ruas, dos guetos e das mobilizações sociais por direitos e visibilidades das dissidências sexuais e de gênero. Consideramos que esses estudos de gênero e ativismos têm conquistado espaços na formação acadêmica em psicologia, mas ainda assim, a concepção normalizadora e compulsória de uma matriz heterossexual na constituição dos sujeitos é hegemonicamente naturalizada pelos discursos e práticas formativas psi. Matriz heterossexual é o termo utilizado por Judith Butler no livro Problemas de Gênero, uma das leituras fundamentais dos estudos queer, publicado originalmente em 1990. Referese ao:

[...] modelo discursivo/epistemológico hegemônico da inteligibilidade do gênero, o qual presume que [...] é necessário haver um sexo estável, expresso por um gênero estável, que é definido oposicional e hierarquicamente por meio da prática compulsória da heterossexualidade (BUTLER, 2015: 258).

A análise das relações de poder, em Foucault, colocou-se como ferramenta necessária para a problematização de um saber-poder sobre as sexualidades que compõe sistemas de pensamento e táticas de regulação da vida, o que em algum momento podemos chamar de patriarcado colonialista, mas que procuramos pensar como um sistema heteronormativo, pela crítica ao binarismo de gênero - fundante do sujeito para muitos referenciais dos saberes psi. O que trazemos aqui, no entanto, não são teorias privilegiadas sobre sexualidades e gênero, como se verdades fossem, em detrimento de outras, mas o ethos que se compõe entre essas subjetividades e corpos dissidentes, contra os dispositivos de normalização.

\section{Tensionamentos curriculares e dissidências transversais}

A indissociabilidade de ensino, pesquisa e extensão, nessa forma e ordem em que os termos se apresentam definidos (MOITA; ANDRADE, 2009), promove uma delimitação, segundo a qual as demandas sociais, sempre por último, são setorizadas, assim como a transmissão e a produção de conhecimento, cada qual associando-se a uma 
série de procedimentos, atividades e metas que devidamente os caracterizem, de modo prescritivo e hierárquico. Entre as prescrições definitivas das atividades de ensino, estariam as disciplinas e suas ementas, enquanto conjunto de aulas e conteúdo. Portanto, apesar da indissociabilidade, ainda se formaliza um espaço-tempo que visa correspondência a um desenho curricular engradado, margeado por disciplinas optativas e obrigatórias, entre as quais se justapõem, se entrelaçam ou se interseccionam as linhas da pesquisa e da extensão.

Buscando as rasuras desse desenho e procurando desconstruir a segmentação no sentido de planos hierárquicos estanques, construímos uma proposta de campo para a pesquisa a partir do estágio em docência, dispondo-nos à oferta de disciplina optativa, com ementa aberta, a qual informalmente denominamos "Sexualidade e Política", inserindo-se entre os conteúdos referenciais acadêmicos, além de produções audiovisuais do cinema, televisivas ou de canais do Youtube, referenciais dos ativismos e dos movimentos sociais - campo geralmente designado aos projetos de extensão.

Nesse contexto, da modalidade de ensino disciplinar, Silvio Gallo (2000) afirma que as propostas interdisciplinares respondem a problemas que as ciências modernas e suas abordagens compartimentadas não seriam mais capazes de responder, a partir de meados do século XX. Gallo (2000: 27) se refere a problemas híbridos, que se constituem como um "novo território de saber, marcado pela interseção de vários campos de saberes", interseção em que se faz possível a produção de saberes múltiplos. Desse modo, a transversalidade não seria apenas estratégia a rasurar o programa e o percurso de uma disciplina, mas sobretudo coloca-se como um eixo de torção que desloca e deforma o plano enrijecido de ensino-pesquisa-extensão. Dessas rasuras e tensões, que se fazem extensãopesquisa-pesquisaensino-ensinoextensão, e que se desfazem desses limites também, acompanhamos suas associações e rupturas que não se restringiram ao espaçotempo de aula. Atravessamos a memória que se atualiza e o projeto que se tensiona das conversas que vivemos e por implicações nas práticas de docência, buscando dissidências da formalidade do currículo, da veridição dos discursos e da normalização dos sujeitos e das sexualidades.

\section{Práticas contradisciplinares nos cotidianos: fora-dentro de um programa disciplinar}

Ao afirmarmos os currículos negociados como campos de possibilidades, 
buscamos dialogar com as concepções de currículos pensados, praticados e desejados como aposta política. Nilda Alves vai nos dizer que a ela interessa pensar os currículos como redes de conhecimentos. Uma vez que esse só acontece:

(...) em um processo, a que poderíamos chamar de tessitura de conhecimentos em redes, tecemos nossos conhecimentos com os conhecimentos de outros seres humanos, permitindo, assim, a produção/criação de novos conhecimentos. Por isso mesmo, não só não podemos identificar todas as origens de nossos tantos conhecimentos como todos eles só podem começar a ser explicados se nos dedicarmos a perceber as intrincadas redes nas quais são verdadeiramente tecidos, enredados (ALVES, 2015: 185).

Desse modo, a concepção de currículo restrita aos espaços-tempos das salas de aula ou dos conteúdos acadêmicos e resultados de pesquisas, amplia-se e estende-se às relações e às ações que ultrapassam tais limites, nos processos cotidianos em que as práticas curriculares se fazem e se desfazem. Pensando com Tomaz Tadeu da Silva (2010: 150), "o currículo tem significados que vão muito além daqueles aos quais as teorias tradicionais nos confinaram. O currículo é lugar, espaço, território. O currículo é relação de poder".

Considerando esses currículos praticados e negociados nos cotidianos, partimos da estratégia de palavras ou temas geradores da pedagogia freireana (FREIRE, 2009), o que operacionalizamos por meio de uma dinâmica inicial com objetos selecionados com a intencionalidade de mediação para o debate. Cada participante poderia escolher um desses objetos dispostos, sendo possível escolherem um mesmo objeto, mas sendo orientados a partilharem individualmente as associações produzidas com as palavras sexualidade e política (temáticas e propostas em ementa da disciplina). Destacamos, a seguir, alguns debates que estes objetos e narrativas suscitaram.

\section{Coisas de meninas, subserviência, erotização, chá e consentimento}

A imagem de um bebê sendo amamentado no seio materno, uma boneca, um carrinho de brinquedo, uma peteca, bijuterias e a embalagem de um perfume - foram alguns dos objetos que levaram às conversas sobre papéis atribuídos na distinção entre "coisas de meninas e "coisas de meninos". Por meio desses objetos, reforça-se a generificação, isto é, a atribuição de gênero, por estereótipos. A boneca fez pensar em notícia recente sobre o assassinato de uma mulher. O namorado se justifica nos meios de comunicação: "ela não me obedeceu". A boneca constrói uma infância de meninas que devem caber a esse lugar de subserviência. Também é sobre a violência na produção de 
corpos e de gêneros a eles atribuídos que conversamos com os objetos sutiã, leque, uma garrafa de rum e um creme anti-celulite. O sutiã é muito bonito, mas é inflexível e obviamente desconfortável. Um modelo feito para agradar aos homens, mas também para que se escondam os seios aos olhos deles. Traz para a mulher uma culpa - você deve se esconder para que se proteja. Com o creme anti-celulite, vem à palavra a fetichização dos corpos femininos, do que também se fala com a narrativa do leque. Consome-se a expectativa de corpos femininos perfeitos, construídos para causar excitação sexual. As pernas e os mamilos, quando expostos, se dispõem a uma erotização. Lembra-se da foto da amamentação. E das delegacias especializadas de atendimento à mulher, nas quais os shorts e saias mais curtos são motivadores atenuantes para quem comete agressão. O dinheiro, no relato sobre o leque, faz lembrar de prostituição. A fantasia com o leque, para a caloura pedindo dinheiro no sinal de trânsito, era só uma brincadeira e um meio de se apresentar em seu rito de passagem. Associada ao dinheiro, porém, a fantasia expôs seu corpo de mulher a uma certeza de acesso irrestrito, como se o dinheiro fosse a senha para um indubitável consentimento. Daí a garrafa de rum, já que o álcool é outra senha para o que vem à conversa como uma cultura de estupro na socialização feminina. Sob efeito de álcool ou pela mediação do dinheiro, os corpos femininos se objetificam de tal forma que não há mais negativa possível, quase sempre determinando a certeza de um consentimento.

\section{Coisas de gay, Madonna, objetificação e fetiche}

Conversamos ainda com Madonna, a mesma que na década de 80 usava um cinto onde se lia Boy Toy, brinquedo de garoto, vestida de noiva, mas com a lingerie exposta, e cantando Like a Virgin, no seu primeiro álbum. Foi a capa do vinil de Like a Prayer que levamos para a conversa. Nesta capa, não se vê rosto ou genitália, apenas uma cintura, mas sabe-se que é uma mulher, e era Madonna, que atravessou a sala de aula em conversa sobre a música e as divas pop como marcadores de estereótipos gays. Gays gostam de boates e são engraçados, divertidos - são os estereótipos. Madonna é uma fronteira: isso é de gay, isso não é de heteros. Onde se vê o estereótipo nessa narrativa, de uma Madonna diva-pop-gay, poderia também se tratar da fetichização como foi discutida nessa intervenção. Não era de Marx ou de Freud que se falava, mas de alguma concepção feita entre um e outro, no senso comum de movimentos sociais, o que não pode deixar de ser um referenciamento. Esse fetiche, porém, não poderá ser referenciado, a não ser como 
este saber subalterno, sem autoria, que assume estatuto de verdade pela proliferação discursiva de coletivos, blogs, youtubers e redes sociais. Madonna-fetiche é a de uma performance bissexual. De uma certa bissexualidade feminina, que se entende como necessariamente disposta ao voyeurismo e ao ménage à tróis, sempre com a presença fantasmagórica de um homem faltante, ou de seu desejo. Dialoga-se, então, com o objetolivro Duas Damas Bem-Comportadas, de Jane Bowles. Ser uma dama, é sentença que as muitas performances de Madonna têm em comum no fazer-se inquietar. Madonna bate o leque, levanta as saias e inscreve na Grande História da Cultura Ocidental a Batalha de Vogue feita nas boates obscuras das gays, das drags e das dikes (sapatonas) americanas dos anos 80. E mesmo no fetichismo de Erotica, a posição de dominatrix não é de um sensualismo convencional. Não é para agradar homens, mas para fazer do corpo seu próprio objeto e instrumento de prazer.

\section{Fora dos gêneros - Sem Tesão Não Há Solução, O Avesso das Coisas, texturas, hipertrofismo, interdição}

Outros objetos-livro foram destacados e estes conversaram com um boneco de plástico e um estojo de maquiagem. Sem Tesão Não Há Solução, livro de Roberto Freire, foi a única conexão direta com o prazer que se experimenta pelas práticas sexuais. $O$ Avesso Das Coisas, obra de aforismos de Carlos Drummond de Andrade, foi escolhido "por falta de opção". Então, esta pessoa que relatou ter escolhido o livro pela capa, colocou-se a pensar sobre como a literatura toca as pessoas, e daí sua atenção ao título, pensando que é avesso o que está por dentro, as coisas que são escondidas - o que tomou forma, para ela, como sexualidade. Avesso é o que está por dentro? Podemos nos perguntar agora. É avesso, mas quando fica ao contrário e se expõe. Na ocasião se disse: os conceitos, quando expressam sensações, limitam a sua experiência. Assim ocorre que essa narrativa conversa com o estojo de maquiagem. Não como atribuição ao feminino, mas a uma sexualidade fora do gênero: de texturas e cores como formas de se apresentar para o mundo. Uma composição. Contrapõem-se essas narrativas, num primeiro movimento, ao binarismo do boneco que representa o personagem Iron Man. Esse Homem de Ferro, que é "brinquedo de meninos", poderia ser mais um ícone entre vários do sexismo e do binarismo de gêneros biologicamente determinados. Essa narrativa, no entanto, vem falar de um corpo inumano que é tido como modelo de masculinidade: uma sexualização hipertrofiada que, no entanto, interdita as genitálias. Essa interdição está no 
Homem de Ferro assim como estaria nas Barbies, se estivesse alguma sobre a mesa.

\section{O corpo que ofende - religião, casamento, agressão masculina e afeminação}

O corpo ofende como objeto sexual. E, no entanto, é sempre objeto desse investimento. Essa foi a conversa vinda da imagem de Nossa Senhora. Em todas as religiões, é o que nos contou esse relato, a interdição à exposição do corpo é muito mais minuciosa e abrangente quando se trata de um corpo feminino. São os seios, as pernas, o colo, por vezes até os ombros que devem ser cobertos. Outra narradora trouxe à conversa o casamento, ligado às religiões cristãs, como forma de criar obrigações para a mulher, em relação ao homem, levando muitas mulheres a práticas sexuais sem prazer, sem desejo. Então, esse homem, que em todas as conversas está posicionado como agressor, violador ou como o sujeito de uma perspectiva, de um olhar que é dominador, que regula e que "fetichiza", vai se apresentar ainda pelo objeto-livro O Homem, de Aluísio Azevedo, que vem à conversa não pelo seu conteúdo, embora coubesse sê-lo, mas ao se afirmar que em psicologia as autorias são majoritariamente masculinas. E eurocêntricas. Desse homem-branco-europeu vêm muitos dos discursos acadêmicos que são referenciais para esta disciplina, como proposta e como foi transcorrida, assim também para esta pesquisa e o artigo em questão, ainda que se propusesse como descolonização de uma escrita. Um único relato, disparado pelo livro de Georgina Martins, Tal Pai, Tal Filho, considerou a posição masculina como não-agressora. Neste livro, classificado como infantil, conta-se a história de um menino bailarino, que foi expulso de casa pelo pai, com quem volta a se encontrar quando adulto. Essa história se associa a outra narrativa, em que se fala de um amigo que pratica dança, mas que só dança com mulheres para não “olharem mal”, sendo que não acontece o mesmo quando mulheres dançam juntas. Este homem não aparece como agressor, mas apenas porque se coloca como vítima, a partir de um olhar de afeminação sobre o seu corpo que dança, que só será masculino se estiver usando na dança o corpo de uma parceira mulher.

\section{Considerações finais: caleidoscópios de falas - dos binarismos de gênero ao coletivo das enunciações}

No curso dessa pesquisa, abordamos o conceito de gênero como performativo, considerando discussões da psicanálise a partir do feminismo em Butler, que reposicionou esses campos, de forma crítica, ao colocar em questão os seus cânones fundamentais: o 
falocentrismo e o drama edípico, na psicanálise, e o sujeito político identitário, no feminismo. Butler propõe a subversão da identidade não apenas como argumento de crítica ontológica, na perspectiva da performance de gênero, mas também como objetivo ou estratégia políticos, o que nos interessou nas conversas dessa disciplina que constituiuse, no percurso cartográfico, como campo de pesquisa pela análise de implicações na prática da docência com os referenciais propostos e no cotidiano dos espaçostempos das aulas e do contexto vivenciado na Universidade e nos movimentos sociais neste período.

Desses processos, construiu-se uma dissertação-narrativa, costurada por analisadores que foram disparados a partir da dinâmica inicial da disciplina, com os objetos-temas geradores, descritos neste artigo, e que também compareceram e atravessaram outras dinâmicas no decorrer do curso, como apresentações de trabalhos e discussões de referências audiovisuais e das redes sociais, tratados na dissertação. Nesse sentido, podemos afirmar que a crítica à normalização, nos referenciais acadêmicos psi, do gênero e da sexualidade, pela reprodução e naturalização da patologização das dissidências à heteronormatividade e ao machismo, foi acompanhada de um problema fundamental para os ativismos identitários em resistência a essas hegemonias, quanto ao qual Butler aponta como caminho estratégico para o feminismo e para a concepção de sujeito político desses ativismos:

Sem a pressuposição ou o objetivo da "unidade", sempre instituído no nível conceitual, unidades provisórias podem emergir no contexto de ações concretas que tenham outras propostas que não a articulação da identidade. Sem a expectativa compulsória de que as ações feministas devam instituir-se a partir de um acordo estável e unitário sobre a identidade, essas ações bem poderão desencadear-se mais rapidamente e parecer mais adequadas a grande número de "mulheres" para as quais o significado da categoria está em permanente debate (BUTLER, 2015a: 40-41).

Considerando a incompletude da categoria "unitária" das mulheres, em suas interseções por marcadores de diferença outros, seguimos para a literatura de Chimamanda Adichie, romancista nigeriana que circulou pelas redes sociais com uma belíssima narrativa, sobre "o perigo de uma história única", quando ela se apresentou como uma "contadora de histórias", e que levamos à sala de aula por sua afirmação: Sejamos Todos Feministas (ADICHIE, 2014: 19). Além dessa proposição de um feminismo que é interseccional, mas que não é identitário, já que se volta para as alianças e para as práticas cotidianas, e não para uma categoria unitária, a conversa proposta e acolhida durante a aula versou sobre esse deslocamento que o feminismo promove no discurso acadêmico, contribuindo com o recurso ao relato vivencial e questionando a 
autoridade científica que fala por e sobre sujeitos - deslegitimados como enunciadores de um "senso comum".

Poderíamos seguir por aí. E encontraríamos na alcunha feminista um salvo conduto humanitário para a generificação. Para que essa convocação de Adichie "sejamos todos feministas" - não nos leve a um outro universalismo, de um feminismo humanista que reivindique certa igualdade entre os gêneros, sem que a categoria dos gêneros seja problematizada, já que são categorias produzidas por um regime significante excludente, e para que dessa forma, não sejamos reféns de qualquer objetivo unitário, porque nas práticas concretas nem sempre nos valem, vamos nos desviar desses argumentos e desses relatos e avançar meses depois do término da disciplina, para as análises de suas narrativas, no encontro com Virginie Despentes, escritora de um manifesto autobiográfico, publicado pela Editora n-1, com o título Teoria King Kong. Compondo com este inominável feminismo de Despentes, é preciso dizer da referência dessa editora a Deleuze e Guattari, pois contrapomos a um feminismo que faz a soma dos gêneros uma proposta da subtração, como produção de multiplicidade.

Na verdade não basta dizer viva o múltiplo, grito de resto difícil de emitir. [...] É preciso fazer o múltiplo, não acrescentando sempre uma dimensão superior, mas, ao contrário, da maneira mais simples, com força de sobriedade, no nível das dimensões do que se dispõe, sempre n-1 (é somente assim que o uno faz parte do múltiplo, estando sempre subtraído dele). Subtrair o único da multiplicidade a ser constituída [...] (DELEUZE; GUATTARI, 1995).

Não se trata de recusar o que conquistamos, em prol dessa categoria unitária que se constituiu como sujeito do feminismo, pois negar a revolução feminista, só tem nos levado a um sentimento de culpa, ao medo diante de uma ameaça constante de punição. Sabemos que não somos inferiores, mas somos a todo momento advertidas de que seremos punidas por isso, porque "nosso poder nos envergonha" (DESPENTES, 2016: 15). Ao considerarmos, no entanto, que à generificação feminina são designados papéis e valorizados atributos essencialmente associados à condição do sexo biológico (BEAUVOIR, 1967) e, muitas vezes, de suas funções reprodutivas, compreendemos que à universalidade dos direitos, legalmente conquistada pelas lutas feministas, não acompanha a equidade do acesso às posições sociais que foram por séculos privilegiadamente masculinas. Para essas posições, o requisito é que se possa ser "como um homem", o que nos coloca não apenas na negação de um corpo, dos nossos próprios corpos, mas de toda precariedade que a condição feminina nos acarreta, inclusive pelo 
julgamento moral que nos restringe apoio social para escolhas que, sendo homens, nem precisaríamos fazê-las. Na defesa irrestrita de uma mulher essencializada como "sujeito do feminismo", contudo, incorremos no equívoco de uma identidade generificada de modo que não superamos a distinção das posições subalternas nas epistemes hegemônicas.

Alcançamos uma pretensa igualdade que nos leva a assumir o ingresso, a permanência e a produtividade acadêmicos como opção indiferenciada em relação aos homens, desde que o problema do gênero permaneça sob o ocultamento dessa universalidade à qual fomos acolhidas sem corporeidade e em silêncio. Interessante observar que tal universalidade, ao ignorarmos esses processos assimilatórios, nos reconduz a produção acadêmica aos tradicionais modelos de legitimação e de autorização, vinculados a este sujeito epistêmico generificado, racializado e espacializado, de forma a conservar os privilégios e as subalternidades sem que se operem deslocamentos mais significativos nessa produção - já que devemos legitimar escritas/discursos a partir das referências produzidas há séculos pelas posições privilegiadas na mundialização colonialista.

Os binarismos de gênero têm sido reafirmados, nos discursos disciplinares em psicologia, como "natureza" normalizada quanto às expressões de gênero e às práticas sexuais, partindo de uma pressuposta compulsoriedade heterossexual. Nesse sentido, dispensamo-nos dessa busca por uma escrita feminina soterrada pela cultura patriarcal. A polifonia do enunciado nos levou a buscar, quanto às identidades, uma multiplicidade de expressões, de montagens e de desmontagens, reconsiderando-se a necessidade de situar a produção acadêmica dissidente quanto ao gênero na voz protagonista da mulher, ou de toda enunciação proveniente do lugar de um não-homem, que deveriam ser libertados de um sistema repressivo, para que a sua verdade possa se expor. Não se trata de desconsiderar os procedimentos de interdição e muito menos as opressões que incidem sobre aqueles e aquelas a quem a posição enunciadora é silenciada. Esses procedimentos concernem à distinção dos especialismos, por uma ordem disciplinar dos discursos, quanto à qual buscamos os deslocamentos por uma produção e um posicionamento que não seriam mais dessa propriedade enunciadora, mas de uma composição, de um aglomerado na enunciação.

Ao buscarmos a heterogênese nos discursos, isto é, a produção de diferença, atravessamos pelos lugares de fala como recortes, emersos e imersos nos processos de 
subjetivação, quanto aos quais passamos a considerar pelos agenciamentos coletivos de enunciação de uma Caosmose, que encontramos nas conversas com Guattari (2006). O descentramento da individuação, ou da expressividade individuada, insere-nos em um plano de coemergências na enunciação, em que se fala com e não se diz sobre. Essa posição implica-nos em buscar, nos saberes subalternos, não o salvo conduto absoluto de uma verdade vivencial, a ser liberada da dominação repressiva. Buscamos, nas produções discursivas desses saberes, além do investimento repressivo que o poder possa efetuar, o seu caráter sobretudo produtivo - de práticas, de políticas, de sujeitos.

Propomos que os dispositivos sexualidade e gênero sejam operados transversalmente nas práticas e desenhos curriculares, o que não justifica a omissão quanto a conteúdos programáticos, que tem por efeito a reprodução de uma hierarquização nos currículos, em detrimento dos modos e conteúdos tradicionalmente preteridos ou silenciados nas formas hegemônicas de produzir conhecimento. Apesar de apostarmos na transversalidade como estratégia que venha a dissolver as fragmentações disciplinares, não podemos abandonar os currículos formais como campo de lutas. Dessa forma, a produção de discursos que buscamos junto aos feminismos e a uma crítica feminista da ciência, é a do exercício de descolonização do pensamento, e de destituição dessa autoridade na administração e na apropriação do conhecimento, pela qual temos sido compelidas a uma universalidade assimilatória.

Nesse caleidoscópio de conexões, recusando-se ao binarismo reafirmado pela universalidade assimilatória e por um feminismo identitário, é que os marcadores de diferença encontram potencial de singularidades - em movimentos que têm se referenciado como interseccionais, por uma outra identidade ou por uma identidade outra, mas também pelas dissipações e contaminações que os encontros e os trânsitos sempre produzem, o que podemos compreender pela performatividade do gênero, que evidencia o transicionamento como expressão da produção de subjetividades que se fazem e se desfazem, a todo tempo, pelos processos de generificação, mesmo para as identidades cis, que também falham na reprodução de modelos, de padrões de normalidade que são sempre equívocos. Situar os agenciamentos coletivos, que produziriam tais singularidades, em narrativas femininas ou no lugar de fala de um não-homem, parecenos conduzir aos discursos de uma essência refletida sobre a escrita ou sobre os modos de produzir conhecimento, uma essência que se oporia diametralmente à masculinidade da matriz heteronormativa, mas que, para esta oposição, ainda manteria como referência 
um binarismo que emerge dessa mesma matriz, desse mesmo processo de normalização.

Por essas análises, e considerando que a proposta de uma disciplina como campo de pesquisa-intervenção tenha sido justamente discutir os referenciais acadêmicos que estão presentes - queira-se ou não - nas práticas das militâncias, devemos afirmar, porém, que não é nada inofensivo que sejam reproduzidas palavras de ordem sem que se considere que articulações epistêmicas as engendram - um exercício crítico que leva a pertencimentos ou, em termos que são mais nossos, a implicações de fato vivenciais. Como também nos orientam, inclusive por essas vivências, ao encontro com certos campos e modos de produção de conhecimento, quanto aos quais também podemos e devemos fazer o exercício da crítica, da desconstrução, ou da subversão.

O marxismo das feministas classistas foi debatido com mulheres proletárias que sequer sabiam ler e escrever, há um século. O existencialismo feminista de Simone de Beauvoir, por mais hermético e eurocêntrico que seja, não se descola de leituras de mundo que pessoas sem tanto estudo formal possam fazer: o questionamento ao destino biológico da mulher; a mulher que não se nasce, torna-se; o feminino que se atribui como masculinidade faltante... será impossível fazer esses debates com mulheres periféricas e seus saberes vivenciais? Cabe-nos sim, pontuar o afastamento das leituras mais estritamente acadêmicas em relação a essas conversas com os espaços não-formais de circulação dos saberes; cabe-nos criticar esse distanciamento como forma de hierarquização do conhecimento e como silenciamento de discursos mantidos como subalternos. Não devemos, porém, deixar essas leituras de fora de qualquer conversa.

Recusar a reapropriação do lugar de fala, pela universalidade assimilatória e pelo binarismo heteronormativo, e fazer desse espaço um terreno baldio. É de uma expropriação reversa que se trata a estratégia de corrosão dessa política de sequestro e de amordaçamento que o conhecimento e a verdade de um sujeito universal nos legaram, legitimados pela constituição das disciplinas. Desse modo, o feminismo de que podemos nos aliançar não se propõe a uma igualdade humanitária, mas a um animalismo, como afirma Preciado (2014):

O feminismo é um animalismo. Dito de outro modo, o animalismo é um feminismo dilatado e não antropocêntrico. [...]. As primeiras máquinas da Revolução Industrial foram máquinas vivas. Assim, o humanismo inventou um outro corpo que chamou de humano: um corpo soberano, branco, heterossexual, saudável, seminal. [...]. Liberdade, igualdade, fraternidade. $O$ animalismo revela as raizes coloniais $e$ patriarcais dos princípios universais do humanismo europeu. $O$ regime de escravidão, e depois o regime do trabalho assalariado, aparece como o fundamento da liberdade 
dos "homens modernos" [...]. O Renascimento, o Iluminismo, o milagre da revolução industrial repousam, portanto, sobre a redução de escravos e mulheres à condição de animais e sobre a redução dos três (escravos, mulheres e animais) à condição de máquinas (re-) produtivas (PRECIADO, 2014).

São as condições de produção subjetiva que nos importam descolonizar e, desse modo, descentrar do antropomorfismo patriarcal, o que nos leva a afirmar a produção de conhecimento feminista, pela compreensão da performatividade de gênero como instrumentos de dissolução da propriedade privada e do privatismo da fala. Aos modos em que transicionam as sexualidades e gêneros dissidentes, que se desviam da normalização de subjetividades, afirmando-se nas performatividades e desfazendo-se dos mapas que oprimem os traços e trajetos de seus corpos, cartografamos a performance dessa composição narrativa, nas dissidências quanto à sua disciplinariedade.

Das identidades e disciplinas interessaram-nos esse fluxo, esse trânsito que imediatamente as precedem na velocidade de sua constituição - nessa passagem aos rizomas, que se atravessam por suas formas, transversalmente. Seguimos a erosão dessas superfícies de contato, supostas lisas, mas nada homogêneas. E nesses atritos é que nos abraçamos, na forma dos corpos que profanamos, como esponjas no caos (ANDRADE, 2008), que absorvem o meio por onde se desmancham.

\section{Referências}

ADICHIE, Chimamanda Ngozi. Sejamos todos feministas. São Paulo: Companhia das letras, 2014.

ALVES, Nilda. Nilda Alves: praticantepensante de cotidianos. Orgs. Alexandre Garcia, Inês Barbosa de Oliveira; textos selecionados de Nilda Alves. Belo Horizonte: Autêntica Editora, 2015.

ANDRADE, Carlos Drummond. Antologia poética. Rio de Janeiro: Record, 2008.

BARROS, Laura Pozzana de.; KASTRUP, Virginia. Cartografar é acompanhar processos. In: PASSOS, Eduardo; KASTRUP, Virginia; ESCÓSSIA, Liliana da.; Pistas do método da cartografia: Pesquisa-intervenção e produção de subjetividade. Porto Alegre: Sulina, 2009.

BEAUVOIR, Simone. O Segundo Sexo 2: A Experiência Vivida. 2a ed. São Paulo: Difusão Européia do Livro, 1967 (pp. 7- 65).

BUTLER, Judith. Problemas de Gênero. $8^{a}$ ed. Rio de Janeiro: Civilização Brasileira, 2015.

DELEUZE, Gilles; GUATTARI, Félix. Introdução: Rizoma. In: , Mil Platôs capitalismo e esquizofrenia. Vol. 1. Rio de Janeiro: Editora 34, 1995.

DESPENTES, Virginie. Teoria King Kong. São Paulo: n-1 edições, 2016.

FREIRE, Paulo. Pedagogia do oprimido. 48. reimp. São Paulo: Paz e Terra, 2009. 
FOUCAULT, Michel. História da Sexualidade 1: A vontade de saber. $2^{\mathrm{a}}$ ed. São Paulo: Ed. Paz e Terra, 2012.

FOUCAULT, Michel. Ditos \& escritos. Ética, Sexualidade, Política. Vol. V. $1^{\text {a }}$ ed. Rio de Janeiro: Forense Universitária, 2004.

GALLO, Sílvio. Transversalidade e educação: pensando uma educação não disciplinar. In: ALVES, Nilda; GARCIA, Regina Leite (orgs.) O Sentido da Escola. Rio de Janeiro: DP\&A, 2000.

GUATTARI, Félix. Caosmose: um novo paradigma estético. São Paulo: Editora 34, 1992.

JESUS, Jaqueline Gomes de. Orientações sobre identidade de gênero: conceitos $e$ termos. Brasília, 2012. Disponível em: http://www.diversidadesexual.com.br/wpcontent/uploads/2013/04/G\%C3\%8ANERO-CONCEITOS-E-TERMOS.pdf (acesso em julho, 2020).

KASTRUP, Virginia. O funcionamento da atenção no trabalho do cartógrafo. In: PASSOS, Eduardo; KASTRUP, Virginia; ESCÓSSIA, Liliana da.; Pistas do método da cartografia: Pesquisa-intervenção e produção de subjetividade. Porto Alegre: Sulina, 2009.

LOURAU, R. Pequeno Manual de Análise Institucional. In: ALTOÉ, S. (Org.) René Lourau: analista institucional em tempo integral. São Paulo: Hucitec, 2004.

MISKOLCI, Richard. A Teoria Queer e a Sociologia: o desafio de uma analítica da normalização. In: Sociologias, Porto Alegre: ano 11, nº 21, jan./jun. 2009, p. 150182.

MOITA, F. M. G. S. C.; ANDRADE, F. C. B. Ensino-pesquisa-extensão: um exercício de indissociabilidade na pós-graduação. In: Revista Brasileira de Educação, v. 14, n. 41, maio/ago. 2009. Disponível em: http://www.scielo.br/pdf/rbedu/v14n41/v14n41a06.pdf (acesso em março, 2016).

PRECIADO, Paul Beatriz. O feminismo não é um humanismo. Disponível em: https://edisciplinas.usp.br/pluginfile.php/4289596/mod_resource/content/0/PRE CIADOFeminismo-nao_e-humanismo.pdf (acesso em julho, 2020).

SILVA, Tomaz. Tadeu da. Documentos de identidade: uma introdução às teorias do currículo. Belo Horizonte: Autêntica, 2010.

ROSEIRO, Maria Carolina F. B. Dissidências em curso: transicionando gêneros nos currículos e nas práticas discursivas em psicologia. 2017. Dissertação de Mestrado. Programa de Pós Graduação em Psicologia Institucional, Universidade Federal do Espírito Santo, Vitória-ES, 2017.

WITTIG, Monique. O pensamento hetero. Texto lido na Modern Language Association Convention, New York, em $1978 . \quad$ Disponível em: https://we.riseup.net/assets/162603/Wittig,\%20Monique\%200\%20pensamento \%20Hetero_pdf.pdf (acesso em julho, 2020).

Maria Carolina F. B. Roseiro 
Alexsandro Rodrigues

Universidade Federal do Espírito Santo

E-mail: xela_alex@bol.com.br

Maria Elizabeth Barros de Barros

Universidade Federal do Espírito Santo

E-mail: barros.bete@gmail.com 